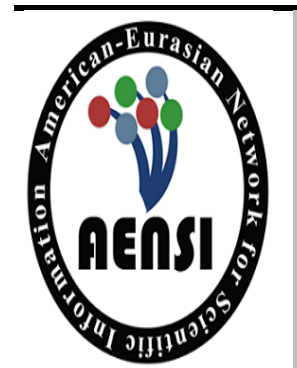

AUSTRALIAN JOURNAL OF BASIC AND APPLIED SCIENCES

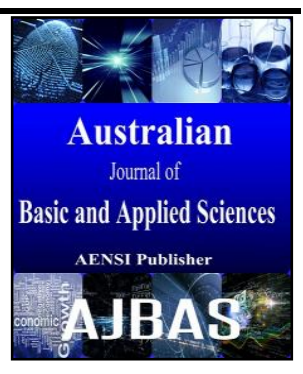

\title{
Histological and Fluorescent Microscope Studies for Evaluation of Carbon Accumulation in Spleen of Birds Within Polluted Areas (Anas platyrhynchos)
}

\author{
${ }^{1}$ Ahmed Al- badri and ${ }^{2}$ Rafel Al-eiqabi \\ ${ }^{1}$ Ahmed Al-badri, Assist prof. Dr.,Department of biology, Wasit University, Wasit, Kut, Iraq. \\ ${ }^{2}$ Rafel Al-eiqabi, Msc student, Department of biology, Wasit University, Wasit, Kut, Iraq.
}

\author{
Address For Correspondence: \\ Ahmed Al-badri, Assist prof. Dr.,Department of biology,Wasit University, Wasit, Kut, Iraq, \\ E-mail: ahmedalmyahi@yahoo.com
}

\section{ARTICLE INFO}

\section{Article history:}

Received 12 October 2017

Accepted 22 November 2017

Available online 6 December 2017

Keywords:

Carbon, Acridine orange, Spleen,

Fluorescent microscope, Electron microscopy.

\begin{abstract}
A B S T R A C T
BACKGROUND: According to WHO for air pollution, each year approximately 3 million people have died, among them, 800,000 people die because of the lung cancer, respiratory and cardiovascular diseases, which are caused by outdoor air pollution. Therefore it became necessary to study about air pollution and the harmful effect of carbon nanoparticles on the different body systems. OBJECTIVE: To attempt to confirm the finding, obtained by light and electron microscope, that carbon particle aggregation through the lymphatic tissues and its incidence on birds which living in the soot polluted area. RESULTS: The microscopic examination with H\&E stain and with PAS and showed black or brown pods in the spleen sections which are considered carbon accumulations. On the other hand, after treating the spleen sections of polluted areas with (AO/EB) double stain the results showed a typical apoptosis feature. The result of SEM of spleen samples of birds which collected from the polluted area showed the ball-shape nanopartcles spread as ultrafin carbon black (UFCB) in the splenic tissue. CONCLUSION: As a result, the most lymphatic tissue of birds (ducks) which affected by carbon particles gathering suffering cellular necrosis and different stages of apoptosis.
\end{abstract}

\section{INTRODUCTION}

The best-studied class of organism are birds, and various investigations have shown their significance as important mobile linkups in the dynamics of natural and human-dominated ecosystems (Cagan, 2006). The spleen is an important lymphoid organ located in the abdomen, directly beneath the diaphragm, and connected to the stomach (Kraal, 1992; Steiniger and Barth, 2000; Jeurissen, 1991). The avian spleen functions as a major blood filtering organ and is the major source of antibody production, it does not function as a reservoir of blood as in mammals and its function is not oriented towards the supply of oxygen (Burke and Simon, 1970). The spleen also plays an important role in erythrocyte destruction phagocytosis and antigen-antibody interactions (Bacha and Bacha, 2012). The spleen is normally round in psittacines and elongated in passerines, it can become tremendously enlarged when stimulated by the demand for antibodies against infections or in a condition such as avian leukosis(Tanimura and Sharma, 1977). Histologically, the spleen is surrounded by a capsule that is rich in smooth muscle and elastic fibers, the parenchyma of the spleen is divisible into the white and red pulp, the white pulp is scattered throughout the spleen and composed of small lymphocyte, it contains sheathed arteries and, occasionally lymphoid nodules, while the red pulp is formed from venous sinuses and anastomosing cords of reticular cells, macrophage, lymphocytes, and red blood cells (Brosnan, 1993). In conjunction with the urbanization, brick industries are rapidly increasing and migrations of people into the city areas pressurize to produce more brick, as a result, more and more brick kilns are being built, at present, over 400,000 people are

Open Access Journal

Published BY AENSI Publication

(C) 2017 AENSI Publisher All rights reserved

This work is licensed under the Creative Commons Attribution International License (CC BY).

http://creativecommons.org/licenses/by/4.0/

\section{(c) (i) Open Access}

To Cite This Article: Ahmed Al- badri and Rafel Al-eiqabi., Histological and Fluorescent Microscope Studies for Evaluation of Carbon Accumulation in Spleen of Birds Within Polluted Areas (Anas platyrhynchos). Aust. J. Basic \& Appl. Sci., 11(14): 34-41, 2017 
engaged in work in the brick industry (Zakeri and Kashefi, 2012; Brosnan, 1995; Asgher and Singh, 2003). Brick manufacturing plants are the most polluted workplaces causing respiratory, gastrointestinal, reproductive, psychosocial and skin diseases.In regions around the world, oil is commonly categorized as one of the highest valued resources an organization can extract from the ground (Skinder et al., 2014). Clearly, the world has a heavy dependence on oil, in addition, the economies of many countries (Inoue and Fujita, 1999). Oil's importance as both a fuel source and a commodity is constantly increasing. As countries around the globe industrialize, oil companies have to expand to new locations in order to meet the growing demand. The economies of many countries, rely almost entirely on its export (Hurtig and Sebastian, 2004; Armstrong et al., 2001)Oil extraction is a complicated process that has the potential for unfortunate consequences, oil spills have extensively contaminated the landscape, damaging both the environment and the health of the people living in the area, the inhalation of smoke from the burning oil wells during the Gulf War has been associated with a host of health problems, various psychological health problems have arisen in those living in the surrounding areas, the types of health effects that derive from a given spill depend largely on the area's level of economic development, the relative speed in which the oil contamination is cleaned up, along with the geographic location of the spill, also impact the consequent health effects(Jungmannet al., 2001; Hurting and Sebastian, 2002; Jean and Sharma, 2000). Oil contamination from drilling processes, however, has adversely affected the people living in these areas by polluting the environment around them, the water, soil and air have been severely tainted by petroleum pollutants, as a result, wildlife, livestock, and humans have been sickened(Ballacheyet al., 2003; Abramson et al., 2004; WHO, 2000). Globally, it is difficult to estimate how many people die off prematurely or get sick due to air pollution because people are exposed to so many different pollutants in various concentrations over their lifetimes. However, according to WHO for air pollution approximately 3 million people have died each year. Among them, 800,000 people die prematurely every year due to lung cancer, cardiovascular and respiratory diseases, which are caused by outdoor air pollution(Wang et al., 1997). (Hurtig and Sebastián, 2002) conducted a study to contrast the cancer rates of people living near oil pits to people who live far from them, their research shows that people who lived in close proximity to the contamination had elevated rates of cancer of the stomach, rectum, skin, soft tissue, kidney, cervix, and lymph nodes, they also found a great increase in hematopoietic cancers among children who were less than 10 years of age (Mehta et al., 2007). Studies in animals have shown that ingestion of carbon tetrachloride increases the risk of liver cancer, EPA has classified carbon tetrachloride as a Group B2, probable human carcinogen (Lindell and Weaver, 2009). The liver and kidney are target organs for carbon tetrachloride toxicity, moderate irritation after dermal application was seen on the skins of rabbits and guinea-pigs, and there was a mild reaction after application into the rabbit eye (Amitai et al., 1998; Farrar et al., 1999). Carbon monoxide (CO) is a nonirritating colorless, odorless gas produced by incomplete burning of carbon containing fossil fuels. The normal concentration in atmosphere is less than $0.001 \%$ and a concentration of $0.1 \%$ can be lethal (Cobb and Etzl, 1991;Aerias, 2005). Mild exposures result in headache, myalgia, dizziness, or neuropsychological impairment (Raub et al., 2000). Severe exposures to carbon monoxide result in confusion, loss of consciousness, or death (Grace and Platt, 1981). It causes thousands of uncalled for deaths each year. Patients who survive the initial poisoning can develop delayed neurologic dysfunction, which occurs in 14-40\% of serious cases (Nelson 2000).

\section{Aim of the study:}

The present histological and ultrastructural studies were undertaken mainly for two reasons:

(1) To attempt to confirm the finding, obtained by light and electron microscope, that carbon particle aggregation through the lymphatic tissues and its incidence on birds which living in the soot polluted area.

(2) In order to evaluate the role of effect of brick manufactories and oil fields on poultry farming comparing to the other healthy bird farms.

\section{MATERIALS AND METHODS}

Eighteen birds of domestic ducks were collected from different healthy and polluted areas of Wasit province, the birds were divided according to the area collected from into three groups (Aldejili, Al Ahdab oil field area, and brick factories area) each group were six birds, all birds should be clinically healthy and devoid of any type of injuries. All domestic ducks were slaughtered and dissected and the spleen samples were taken from the abdomen region and were fixed in $10 \%$ formalin for (72) hours, then and there washed up in tap water for 2-3 hours and then moved the samples to numerous histological techniques as followed: dehydration, clearing, infiltration, embedding, cutting and staining with hematoxylin and eosin (H\&E) stain, periodic acid sciff (PAS) stain for appearing the general structure of the spleen and todetect aggregations of carbon in paraffin sections. In addition to acridine orange/ ethidium bromide (AO/EB) double stain to detect apoptosis occurred in the lymphoid cells splenic tissue, also the electron microscopy examinations were performed to detect the carbon nanotubes in the spleen sections. 
Owing to performance, with accurately, carbon gathering in the different lymphatic tissue for birds which relate in the polluted areas by carbon compounds, scanning electron microscope (SEM) technique was utilized. The samples were subjected to the following steps:

Fixation with glutaraldehyde, washing by phosphate buffer, post-fixation with osmium tetroxide, dehydration by ethanol or acetone solutions, critical point drying (CPD), coating, viewing specimens in SEM and image analysis.

\section{RESULT AND DISSCUSION}

\section{1: Histological and Fluorescent microscope result of healthy area:}

The histological examination by H\&E stain and PAS stain of the spleen samples showed a connective tissue capsule surrounding two main compartment, the white pulp and the red pulp. The cross section of the spleen of the domestic duck showing the C.Ttrabecula from capsule penetrates the splenic tissue, and the lymphatic node, and central artery also present (Fig. 1, 2). These facts were compatible with. (Reina and Georg, 2005)in the human; (Mark, 2006); in rat and in chicken by (Bacha and Bacha, 2012).

On the other hand, the microscopic examination with H\&E stain in addition to, PAS stain showed absence of any carbon accumulation its only showing the basic histological structure of the spleen (Fig. 1, 2). This result approved by(Sheng Tao Yang et al., 2008), they compared the histologcal observations to the control group and the carbon exposed group of mice, the control was clean while the carbon exposed group had aggregations of carbon nanotubes.

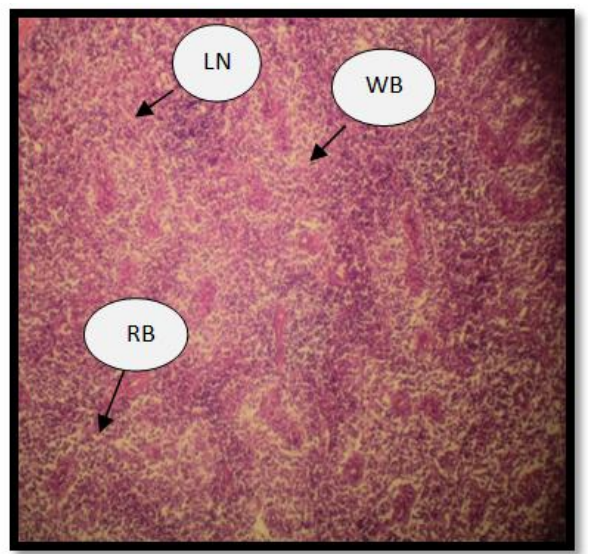

Fig. 1: Cross section of the spleen of the domestic duck (healthy area) showing the red bulb (RB), white bulb (WB) and the lymphatic nodule (LN) ( H\&E stain, 20X).

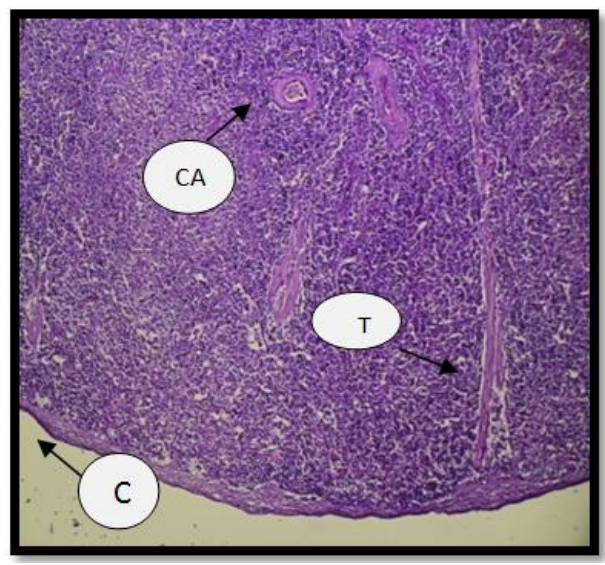

Fig. 2: Cross section of the spleen of the domestic duck (healthy area) showing the capsule (C), central artery (CA), and the trabecula (T) (PAS stain, 20X).

\section{Polluted areas:}

The histological observation was carried out to determine the accumulation of carbon. The microscopic examination with H\&E stain and with PAS (periodic acid sciff stain) and showed black or brown pods in the spleen sections which are considered carbon accumulations for the samples taken from oil fields(Fig. 3, 4). 


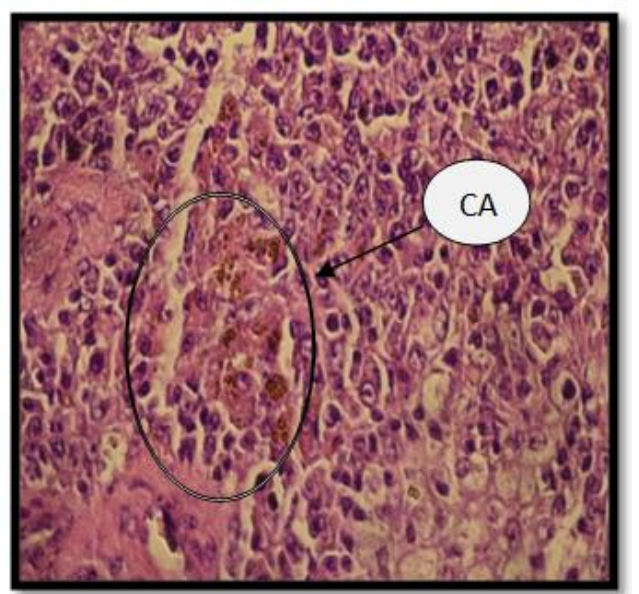

Fig. 3: Cross section of spleen of the domestic duck (oil fields area) showing the carbon aggregation (CA) (H\&E stain, 100X).

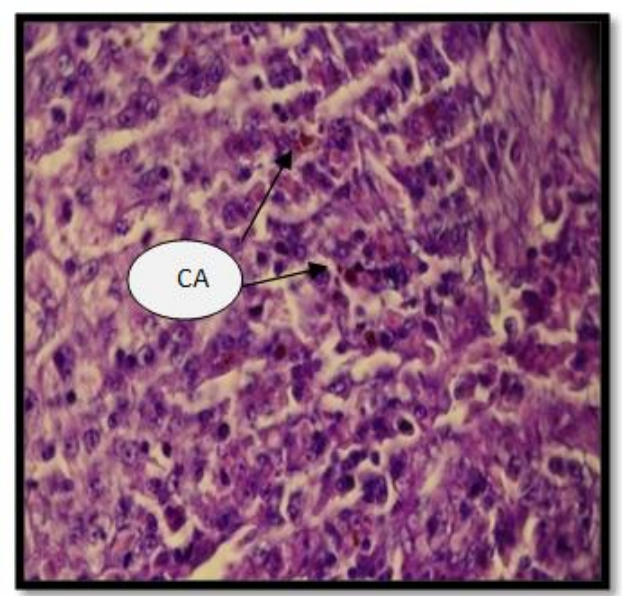

Fig. 4: Cross section of spleen of the domestic duck (oil fields area) showing the carbon aggregation (CA) (PAS stain, 100X).

The aggregations of carbon were slightly higher in the samples taken from areas near brick factories than those taken from areas near oil fields (Fig. 5, 6). These results are similar to the finding of(XiaoyongDenget al., $2009)$;(Simona Clichiciet al.,2013)in mice;(Kuan Liu et al., 2015)in rat.

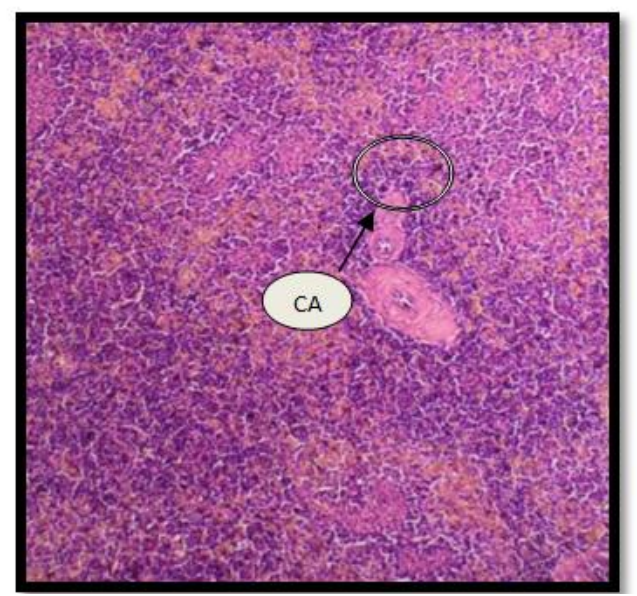

Fig. 5: Cross section of spleen of the domestic duck (brick factories area) showing the carbon aggregation (CA) (H\&E stain, 20X). 


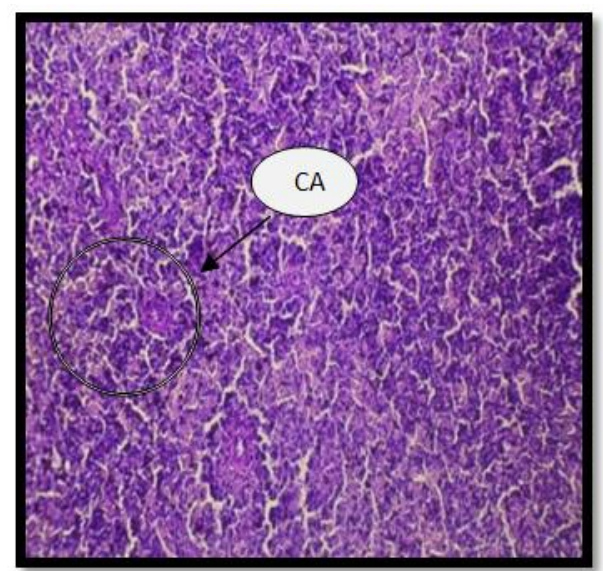

Fig. 6: Cross section of spleen of the domestic duck (brick factories area) showing the carbon aggregation (CA) (PAS stain, 40X).

On the other hand, after treating the spleen sections of polluted areas with acridine orange/ ethidium bromide double stain and examined with fluorescence microscope, the results showed a typical apoptosis feature, such as obvious chromatin condensation and slight nuclear fragmentation, the cells with yellow color indicate the early DNA fragmentation, while cells with orange color indicate full DNA fragmentation (Fig. 7, 8). These results were similar to (Simona Clichici et al., 2013), in vertebrates he mentioned that the cells that was unbroken with acridine orange/etheidium bromide double stain appeared in green color while the stained cells appeared in yellow color as an indicator of early apoptosis and red color as late apoptosis.

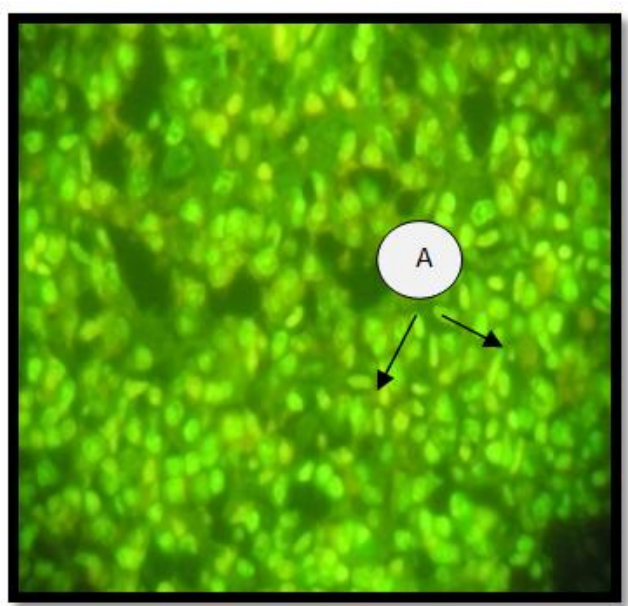

Fig. 7: Section of the spleen showing apoptotic cells (A) with yellow and orange color (AO stain, 40X).

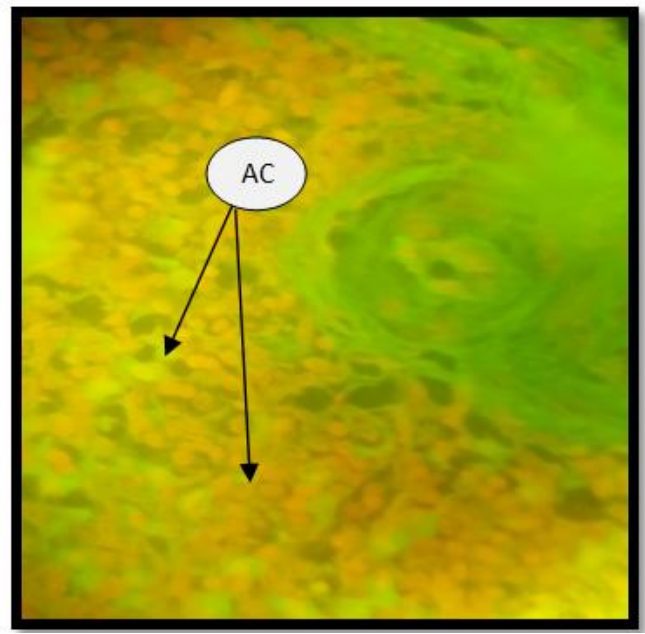

Fig. 8: Fluorescent microscope section of spleen in the domestic duck (brick factories area) showing the apoptotic cells in orange color (AC) (AO stain, 40X). 


\section{2: Electron microscopy results: \\ Healthy area:}

The ultrastrcture study of the spleen of duck in the polluted area was worked by scanning electron microscope. The examination showed the fine structure of the spleen including three dimensions of reticular tissue that consist from splenic cord. Between the splenic cords lattal of splenic sinusis, which have irregular fenestrea in its wall. The findings were similar to the descriptions of (Myamoto et. al., 1980) in spleen of fowl, and same as fine structure that already reported in the mouse spleen by (Yoshiaki Hataba et al., 1981).

\section{Polluted area:}

The result of SEM of spleen samples of birds which collected from polluted area showed the ball-shape nanopartcles spread as ultrafin carbon black (UFCB) in the splenic tissue. These nanopartcles are widespread in the samples of brick factories area than the samples of oil fields area (Fig 9, 10). All these results similar and conformity with the histological technique findings. This result was analogous to result of same authors they describes the gathering of carbon nanotubes (CNT) as (UFCB), multi-walled carbon nanotubes (MWCNT) and single walled carbon nanotubes (SWCNT) in the pulmonary tissue of experimental mice (Mishra et. al., 2015). Whilst (Yang et al., 2017) mentioned, by scanning electron microscopy, the aggregation and toxicity of carbon nanotubes in the central nervous system, and in monkeys (Tukashi Miura et al., 2000).

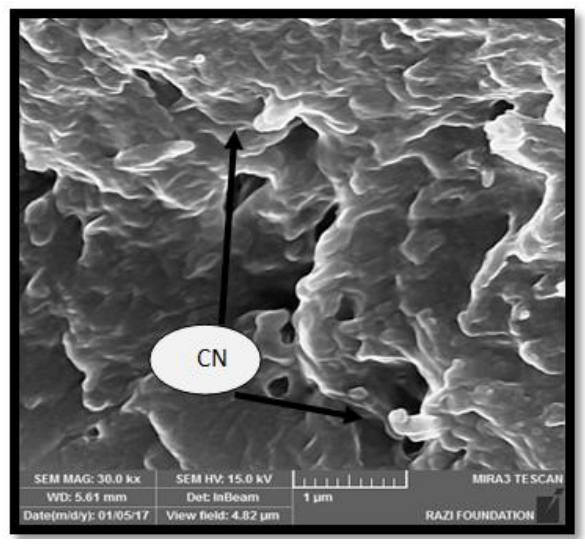

Fig. 9: Scanning electron microscopy image of spleen (oil fields area) showing particals $(\mathrm{CN})$ at magnification power of $1 \mu \mathrm{m}$.

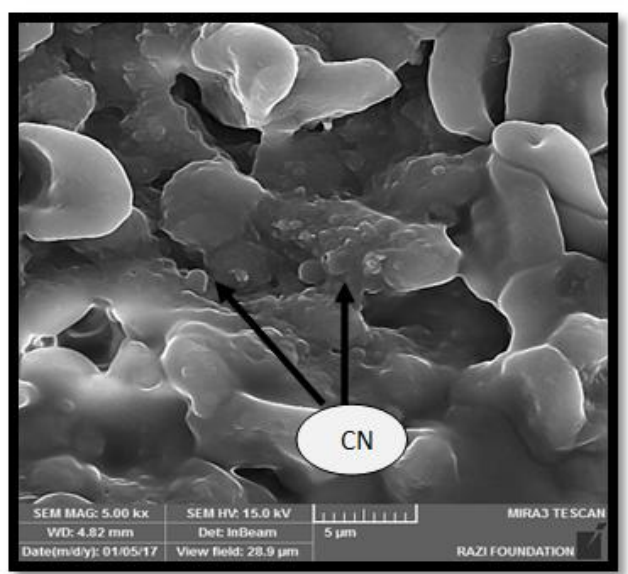

Fig. 10: Scanning electron microscopy image of spleen (brick factories) showing the carbon nanoparticals (CN) at magnification power of $5 \mu \mathrm{m}$.

In this work, we tried to remking call act of carbon in the spleen of birds in polluted areas, which has a greater accumulation than lymphoid tissue in the body and only one organ that interposed the blood circulation and the site of destruction of aged RBCs, as well as aggregation and deposition if same substances that enter blood stream. these particles arise event of fractions, and travel into blood circulation and eventually lead to forming a thrombus. Migration of these particles into spleen and liver from like prostheses.

The following points are recommended: 
1. Histochemestry and scanning electron microscope studies of carbon aggregation in lymphatic tissue of birds.

2. Study of carbon aggregation in the lymphnode and serous membranes of large animals which breeding in the polluted area.

3. Study of aggregation effect of cadmium and lead in lymphatic tissue of mammales or birds breeding in oil field area.

\section{ACKNOWLEDGMENT}

I would like to express my sincere gratitude to my supervisors Dr. Ahmed Mahdi Al- Badri for his helpful gaudiness and advice and Dr. Melad Khalaf Mohammed for her valuable support, continuous gaudiness and interest, she taught me how good searcher should be and made me take the right choice throughout the period of this research.Deeply thanks to Dr. AliShuaafor his help, also I would like to thank with love my Family for their support and sharing all moments.

\section{REFERENCES}

Cagan, H.S., 2006. Increasing awareness of avian ecological function, TRENDS in Ecology and Evolution 21(8): 464-471.

Kraal, G., 1992. Cells in the marginal zone of the spleen. Int. Rev. Cytol., 132: 31-73.

Steiniger, B. and P. Barth, 2000. Microanatomy and function of the spleen. Adv. Anat. Embryol. Cell Biol., 151(4): 1-101.

Jeurissen, S.H.M., 1991. Structure and Function of the Chicken Spleen. Res. Immunol., 142: 352-55.

Burke, J.S. and G.T. Simon, 1970. Electron Microscopy of the Spleen. I. Anatomy and Microcirculation. Am. J. Pathol., (58): 127-55.

William, J. Bacha and Linda, M. Bacha, 2012. Color atlas of veterinary histology, third edition, pp: 89-104.

Tanimura, N. and I.M. Sharma, 2001. Induction of Apoptosis T cells in the bursa of fabricius and cecal tonsils In vitro by the 17-Kda Nonstructural Protein of during the acute phase of infectious bursal disease Infectious bursal disease Virus: Possible Role in Viral virus infection in chickens. Avian Dis., 41: 638-45.

Brosnan, D., 1993. Final Test Report for U. S. EPA Test Program Conducted at Pine Hall Brick Plant, Madison, NC, U. S. Environmental Protection Agency, Research Triangle Park, NC 3: 1-67.

Zakeri, A. and P. Kasef, 2012. A Study of Programmed Cell Death in Cecal Tonsil of Infected Chickens by Infectious Bursal Disease Virus with Using Electronic Microscope, American-Eurasian J. Agric. \& Environ. Sci., 12(6): 733-736.

Brosnan, D., 1995. Emission Testing at a Structural Brick Manufacturing Plant--Final Emission Test Report for Testing at Belden Brick Company, Plant 6, Sugarcreek, Ohio, U. S. Environmental Protection Agency, Research Triangle Park, NC (11): 3-20.

Ashger, M.S. and A.L. Singh, 2003. Land degradation through brick kiln: A case study of Aligarh, India. Indian Journal of Regional Sciences, 35: 77-84.

Skinder, B.M., A.K. Pandit, A.Q. Sheikh and B.A. Ganai, 2014. Brick kilns: cause of atmospheric pollution. J. Pollut. Eff. Cont., (2):110.

Inoue, M. and A. Fujita, 1999. Lysis of Myelocytes in chickens Infected with infectious Bursal Disease virus. Vet. Pathol., 36: 146-151.

Hurtig, A.K. and Sebastián, 2004. Oil development and health in the Amazon basin of Ecuador: the popular epidemiology process. In Social Science \& Medicine, 60: 799- 807.

Armstrong, B., J.A. Córdoba, M.S. Sebastián, C. Stephens, 2001. Exposure and CancerIncidenceNear Oil Fields in the Amazon basin of Ecuador. Journal of

Jungmann, A., N. Herman and H. Muller, 2001. virus replication in productively infected cells as well as antigen-negative cells in their vicinity, Journal of General Virology, 82: 1107-1115.

Hurtig, A.K. and M.S. Sebastián, 2002. Geographical Differences in Cancer Incidenc in the Amazon Basin of Ecuador in Relation to Residence Near Oil Fields. International Journal of Epidemiology, 31: 1021-1027.

Jean, K. and M. Sharma, 2000. IBDV-induced bursal T lymphocyte inhibitmitogenic effects and immune system weakness were not only by response of normal splenocytes. Immonology and Immonopathology, 74: 4757.

Ballachey, B.E., J.L. Bodkin, D. Esler, C.H. Peterson, S.D. Rice and J.W. Short, 2003. Longterm ecosystem response to the Exxon-Valdez oil spill.In Science, 302(5653): 2082.

Abramson, M.J. A.B. Forbes, D.C. Glass, J.F. Ikin, P. Ittak, H.L. Kelsall, D.P. McKenzie, M.R. Sim, 2004. Respiratory Health Status of Australian Veterans of the 1991 Gulf War and the Effects of Exposure to Oil Fire Smoke and Dust Storms.In Thorax, 59: 897-903.

WHO, 2000. Guidelines for Air Quality. Geneva: World Health Organization. 
Wang, P.Y., T. Kaneko, H. Tsukada, M. Nakano, and A. Sato, 1997. Dose- and route-dependent alterations in metabolism and toxicity of chemical compounds in ethanol-treated rats: difference between highly (chloroform) and poorly (carbon tetrachloride) metabolized hepatotoxic compounds. ToxicolApplPharmacol, 142: 13-21.

Mehta, S.R., S. Das, S.K. Singh, 2007. Carbon Monoxide Poisoning, 63(4): 362-365.

Lindell, K. and M.D. Weaver, 2009. Carbon Monoxide Poisoning, N Engl J Med., 360: 1217-25.

Amitai, Y., Z. Zlotogorski, V. Golan-Katzav, A. Wexler and D. Gross, 1998. Neuropsychological impairment from acute low-level exposure to carbon monoxide. Arch Neurol, 55: 845-8.

Cobb, N. and R.A. Etzl, 1991. Unintentional carbon monoxide related deaths in United States, 266: 659-63.

Raub, J.A., N. Mathieu, N.B. Hampson and S.R. Thom, 2000. Carbon monoxide poisoning-a public health perspective. Toxicology, 145: 1-14.

Grace, T.W. and F.W. Platt, 1981. Sub acute poisoning. 246: 1698-700.

Farrar, C., J. Neil and J. Howle, 1999. Magmatic Carbon Dioxide Emissions at Mammoth Mountain, California. USGS Water Resources Investigation Report, pp: 98-4217.

Nelson, L., 2000. Carbon Dioxide Poisoning.Summary of physiological effects and toxicology of CO2 on humans.Emerg. Medicine, 32(5): 36-38.

Air Quality Science IAQ Resource Center (Aerias). 2005. Carbon Dioxide: A Common Indoor Air Pollutant.

Reina, E.M. and K. Georg, 2005. Structure and function of the spleen, Nature, 5: 606-616.

Mark, F.C., 2006. Normal Structure, Function, and Histology of the Spleen, Toxicologic Pathology, 34: 455-465.

Sheng, Tao Yang, Xiang, Wang, Guang Hia, Yiqun, Gu, Tiancheng, Wang, Haiyu, Nie, Cuicui, Ge, Haifang, Wang and Yannfang, Liu, 2008. Long term accumulation and low toxicity of single walled carbon nanotubes in intravenously exposed mice, Toxocology letters, (181): 182-189.

Xiaoyong Deng;FeiWu; Zhen Liu; Man Luo; Ling Li, Qingshun Ni, Yang, Z.W. Liu, R.P. Allaker, P. Reip, J. Oxford, Z. Ahmad and G. Ren, 2010. nanoparticle functionalityand toxicity on the centralnervous system, J. R. Soc. Interface, 7: 411-422.

Simona, C.R.B. Alexandru, C. Cornel, F. Adriana and T. Flaviu, 2013. Short-term splenic impact of singlestrandDNA functionalized multi-walled carbonnanotubes intraperitoneally injected in rats, Journal of Applied Toxicology, 34(4): 332-344.

Kuan, Liu, Peng-cheng Liu, Xing, Wu and A.O. Dual, 2010. EB Staining to Detect Apoptosis in Osteosarcoma Cells Compared with Flow Cytometry, Med SciMonit Basic Res., 21: 15-20.

Miyamoto, H., H. Seguchi and K. Ogawa, 1980. Scanning Electron Microscopic Study of the Red Pulp of Mouse SpleenJ. Electron Microsc, pp: 29: 158.

Yoshiaki Hataba; Yuji Kirino and Teruo Suzuki, 1981. Scanning Electron Microscopic Study of the Red Pulp of Mouse Spleen, J. Electron Microsc, 30(1): 46-56.

Anurag Mishra, A. Stueckle, R. Robert, R. Mercer, Raymond Derk, Yon Rojanasaku, Vincent Castranova, and Liying Wang, 2015. Identification of TGF- receptor-1 as a key regulator of carbon nanotube-induced fibrogenesis. J. Cell MolPhysiol, 309: 821-833.

Yang, Z., W. Allaker, P. Reip, J. Oxford, Z. Ahmad and G. Ren, 2010. A review of nanoparticle functionality and toxicity on the central nervous system. J. R. Soc. Interface, 7: 411-422.

Takashi, Miura, Tatsuo, Shimada, Koichi, Tanaka, Masao, Chujo, Yuzo, Uchida, 2000. Lymphatic drainage of carbon particles injected into the pleural cavity of the monkey, as studied by video-assisted thoracoscopy and electron microscopy, J Thorac Cardiovasc Surg,120: 437-47. 